\title{
A BOA-FÉ PROCESSUAL OBJETIVA À LUZ DO NOVO CÓDIGO DE PROCESSO CIVIL: UMA NORMA DIRIGIDA A TODOS OS PARTICIPANTES DO PROCESSO
}

THE GOOD FAITH IN THE LENGTH OF THE NEW CIVIL PROCESS CODE: A STANDARD ADDRESSED TO ALL PARTICIPANTS IN THE

PROCESS

\section{Lígia Maia de Oliveira Miranda ${ }^{1}$}

ISSUE DOI: $10.21207 / 1983.4225 .398$

\section{RESUMO}

Considerando as recentes inovações na Dogmática Processual Civil Brasileira, sobretudo com o advento do Novo Código de Processo Civil, o presente estudo tem por objetivo debater a inserção da boa-fé objetiva como norma processual de caráter fundamental que, pela sua natureza, impõe-se a todos os sujeitos processuais, indistintamente, devendo ser observada em todas as fases processuais. Pretende-se, portanto, discutir a essência conceitual da referida norma; a evolução do princípio da boa-fé até a aquisição do status que lhe fora conferido pelo Novo CPC, tecendo a distinção do tratamento da boa-fé no CPC/1973 e o CPC/2015; e, finalmente, discutir as possíveis repercussões práticas da consagração da aludida norma processual fundamental.

\footnotetext{
${ }^{1}$ Possui graduação em Direito pelo Centro de Ensino Superior do Amapá (2013). Pósgraduanda em Direito Processual Civil pela Universidade Anhanguera - UNIDERP. Possui formação como pregoeira. Advogada com inscrição na OAB/PA sob o no 19.885. Tem experiência na área jurídica. Atualmente atua como Chefe de Controle Interno no Serviço de Saneamento Ambiental de Marabá - PA, entidade autárquica municipal.
} 
Palavras-chave: Boa-fé Objetiva Processual. Novo CPC. Princípio. Norma Fundamental Processual.

\section{ABSTRACT}

Considering the recent innovations in Dogmatic Brazilian Civil Procedure, especially with the advent of the new Processual Civil Code, the present study aims to discuss the inclusion of objective good faith as a procedural rule of fundamental character that by their nature are binding on all procedural subjects, without distinction, should be observed in all procedural stages. It is intended, therefore, to discuss the conceptual essence of this rule; the evolution of the principle of good faith to the acquisition of the status conferred on him by the New PCC, expounding good faith treatment of distinction in PCC/1973 and PCC/2015; and, finally, discuss the possible practical implications of the consecration of the aforementioned fundamental procedural rule.

Keywords: Objective Procedure Good Faith. New PCC. Principle. Fundamental Rule Procedure.

\section{INTRODUÇÃO}

O Novo Diploma Processual Brasileiro (Lei $\mathrm{n}^{\circ} 13.105$ de 16 de março de 2015) positivou as denominadas "Normas Processuais Fundamentais", insertas em seu Capítulo I, cujo conteúdo, nos dizeres de THEODORO JR. "[...] servirá de premissa interpretativa de todas as técnicas trazidas na nova legislação" "2 de sorte que toda a sistemática processual civil deverá ser regida e exercida sob a égide das referidas normas.

Com efeito, a boa-fé objetiva ganha força no cenário jurídico contemporâneo, eis que o advento do Novo CPC conferiu-lhe o status de norma processual fundamental, dirigida a todos aqueles que participam do processo, segundo a inteligência do artigo $5^{\circ}$ do referido diploma, onde se lê: "Art. $5^{\circ}$. Aquele que de qualquer forma participa do processo deve comportar-se de acordo com a boa-fé.".

\footnotetext{
2 THEODORO JR., Humberto et al. Novo CPC: Fundamentos e Sistematização. Rio de Janeiro: Forense, 2015. p. 32.
} 
A importância do debate proposto pelo presente estudo revelase ao passo em que a boa-fé emerge como cláusula geral processual, apta a produzir efeitos sobre todos os sujeitos que atuarem no processo e em todas as fases processuais, o que certamente acarretará em implicações e consequências, ainda incertas, porque o novo diploma processual, além de não conceituá-la, também não indica quais seriam as decorrências de sua inobservância.

Desse modo, o presente estudo tratará, em seu capítulo inaugural, da concepção de boa-fé processual, conceituando e distinguindo a boa-fé objetiva da subjetiva.

Em seu segundo capítulo, analisará a evolução da boa-fé no âmbito processual brasileiro, esclarecendo o tratamento conferido àquela pelo $\mathrm{CPC} / 73$.

Finalmente, trataremos da introdução, pelo novo diploma processual, da boa-fé objetiva como norma processual fundamental, dirigida a todos os demais participantes do processo, além de seus possíveis reflexos no exercício jurisdicional, inclusive no que tange ao descumprimento da norma processual fundamental em questão.

\section{A BOA-FÉ OBJETIVA NO DIREITO PROCESSUAL CIVIL BRASILEIRO}

\subsection{FUNDAMENTOS E CONCEITO DE BOA-FÉ OBJETIVA PROCESSUAL}

Conforme salientado no ponto introdutório do presente estudo, a boa-fé objetiva é classificada pelo Novo Código de Processo Civil como uma Norma Fundamental Processual. Nos dizeres de DIDIER JR., denomina-se a norma de fundamental porque ela "[...] estrutura o modelo de processo civil brasileiro e serve de norte para a compreensão de todas as demais normas jurídicas processuais civis" 3 .

3 DIDIER JR., Fredie. Curso de Direito Processual Civil: Introdução ao Direito Processual Civil, Parte Geral e Processo de Conhecimento. 17 a ed. Salvador: JusPodvm, v.1, 2015. p. 61. 
Especificamente no tocante à boa-fé objetiva, denotada pelo artigo $5^{\circ}$ do Novo $\mathrm{CPC}$, pode-se dizer que a referida norma tem o condão de balizar as condutas dos sujeitos processuais, a fim de que se portem de maneira leal e proba, contribuindo para um justo deslinde processual. Corroborando a essa afirmativa, explica THEODORO JR. que "O princípio da boa-fé objetiva consiste em exigir do agente a prática do ato jurídico sempre pautado em condutas normativamente corretas e coerentes, identificados com a ideia de lealdade e lisura" 4 .

No mesmo sentido, DIDER JR., aponta que a boa-fé objetiva processual trata-se de um princípio a ser observado, segundo o qual os comportamentos de todos aqueles que participam do processo, devem respeitar um padrão ético de conduta, correspondendo àquilo que, objetivamente, se entende como devido. ${ }^{5}$

Observa-se, portanto, que a boa-fé objetiva consiste em um parâmetro a ser aplicado no exercício das condutas processuais, devendo sêlo realizado por todos os sujeitos que atuarem no processo, em quaisquer hipóteses ou fases processuais, uma vez que o legislador não delimitou o alcance da aludida norma, ao contrário, conferiu-lhe amplitude ao erigirlhe ao status de fundamental.

Ademais, cumpre destacar que a boa-fé objetiva foi inserida na nova dogmática processual civil como uma cláusula geral processual, o que quer dizer que ela se trata de uma hipótese normativa ampla, conforme os ensinamentos de THEODORO JR:

[...] a boa-fé aparece no direito processual, como em todo o ordenamento jurídico, sob a roupagem de uma cláusula geral, e, assim, tem a força de impregnar a norma que veicula de grande flexibilidade. Isso porque a característica maior dessa modalidade normativa é a indeterminação das consequências de sua inobservância, cabendo ao juiz, nos limites do debate processual e em comparticipação com as partes, avaliar e determinar

\footnotetext{
4 THEODORO JR., Humberto et al. Novo CPC: Fundamentos e Sistematização. Rio de Janeiro: Forense, 2015. p. 135.

5 DIDIER JR., Fredie. Editorial 45. Bahia, 2008. Disponível em: $<$ http://www.frediedidier. com.br/editorial/editorial-45/>. Acesso em: 01 fev. 2016.
} 
seus efeitos, adequando-os às peculiaridades do caso concreto. ${ }^{6}$

Tecidos esses esclarecimentos primordiais, é possível deduzir que não há como restringir a boa-fé a uma mera formalidade conceitual, eis que a sua marca é de amplitude, tanto no seu alcance, quanto em sua natureza, pois ela não se trata de uma espécie normativa fechada, mas de uma cláusula geral processual.

\subsection{BOA-FÉ OBJETIVA X SUBJETIVA}

A fim de melhor compreendermos o alcance da norma fundamental presente no artigo $5^{\circ}$ do Novo CPC, qual seja a boa-fé objetiva, sobretudo no que diz respeito à obrigatoriedade de sua observância por todos os sujeitos processuais, é necessário que façamos uma pontual distinção entre a boa-fé objetiva e a subjetiva.

Importa destacar, desde logo, que embora a boa-fé objetiva esteja assumindo cada vez maior destaque em nosso ordenamento jurídico, a boa-fé subjetiva continua vigente e exigível, presente tanto no direito material quanto no processual civil. ${ }^{7}$

Como seu próprio nome nos leva a inferir, a boa-fé subjetiva está intimamente ligada ao sujeito e àquilo que se passa em seu foro íntimo quando da prática do ilícito processual, especificamente no que concerne à sua intenção ao fazê-lo, se dolosa ou culposa.

Segundo os ensinamentos de TARTUCE:

A boa-fé subjetiva [...] consiste em uma situação psicológica, um estado de ânimo ou de espírito do agente que pratica determinado ato ou vivencia dada situação, sem ter ciência do vício que a inquina.

\footnotetext{
6 THEODORO JR., Humberto et al. Novo CPC: Fundamentos e Sistematização. Rio de Janeiro: Forense, 2015. p. 136.

7 TARTUCE, Flávio. Boa-fé Objetiva Processual: Reflexões quanto ao atual CPC e ao Projeto do Novo Código. In: Jusbrasil, 2014. Disponível em: <http://flaviotartuce.jusb rasil.com.br/artigos/121822496/boa-fe-objetiva-processual-reflexoes-quanto-ao-atual-cpce-ao-projeto-do-novo-codigo>. Acesso em: 01 fev. 2016.
} 
Para que uma conduta esteja em consonância com a boa-fé subjetiva é imprescindível a presença da boa intenção ou, no mínimo, a ausência de má intenção. [...] Por isto, a formação de um juízo de valor quanto a se um determinado agente atuou com boa-fé no plano subjetivo exige perquirição a respeito da intenção que o moveu a praticar o ato. ${ }^{8}$

Pontua, ainda, SANTOS:

A boa-fé subjetiva, que também é conhecida como boa-fé crença, decorre de avaliação individual e equivocada que a pessoa possui e que faz acreditar que está atuando conforme o direito, o sujeito se encontra em completo estado de ignorância sobre as características da situação jurídica. A pessoa acredita ser titular de um direito que, na realidade, não tem, porque esse direito só existe de maneira aparente. ${ }^{9}$

Observa-se, portanto, que para que alguém aja em conformidade com a boa-fé subjetiva é de suma importância que ignore a condição de ilicitude do ato praticado.

Cuidemos, pois, de tecer a distinção entre a boa-fé subjetiva e objetiva.

O tópico anterior cuidou de esclarecer o que seria a boa-fé objetiva processual, momento no qual pudemos concluir que a mesma materializa-se como um dever de conduta em conformidade com os parâmetros

\footnotetext{
${ }^{8}$ TARTUCE, Flávio. Boa-fé Objetiva Processual: Reflexões quanto ao atual CPC e ao Projeto do Novo Código. In: Jusbrasil, 2014. Disponível em: <http://flaviotartuce.jusb rasil.com.br/artigos/121822496/boa-fe-objetiva-processual-reflexoes-quanto-ao-atual-cpce-ao-projeto-do-novo-codigo>. Acesso em: 01 fev. 2016.

${ }^{9}$ SANTOS, Leide Maria Gonçalves. A Boa-Fé Objetiva no Processo Civil: A Teoria dos Modelos de MIGUEL REALE aplicada à Jurisprudência Brasileira Contemporânea. 2008. 287 f. Dissertação (Mestrado em Direito Processual Civil) - Universidade Federal do Espírito Santo, Vitória, $2008 . \quad$ Disponível em:<http://www.dominiopublico.gov.br/download/teste/arqs/cp087247.pdf>. Acesso em: 02 fev. 2016.
} 
objetivamente considerados como corretos. Trata-se de uma norma, uma regra de conduta dirigida a todos os participantes do processo. ${ }^{10}$

Por se tratar de uma norma, conforme anteriormente observado, a boa-fé objetiva não visa à análise das intenções do sujeito processual ao praticar determinado ato, mas diz respeito à necessidade que é imposta a esse sujeito, de agir em conformidade aos padrões ético-jurídico exigidos.

Vejamos os ensinamentos de THEODORO JR., que nesse sentido, assevera:

Há, porém, uma outra visão de boa-fé, que se desprende do subjetivismo para se localizar objetivamente no comportamento do agente, como exigência de ordem ético-jurídica. Essa boa-fé objetiva $[\ldots .$.$] .$

O princípio da boa-fé objetiva consiste em exigir do agente a prática do ato jurídico sempre pautado em condutas normativamente corretas e coerentes, identificados com a ideia de lealdade e lisura. Com isso, confere-se segurança às relações jurídicas, permitindo-se aos respectivos sujeitos confiar nos seus efeitos programados e esperados. ${ }^{11}$

Assim, a boa-fé objetiva de que trata o artigo $5^{\circ}$ do $\mathrm{CPC} / 2015$ tem alcance indiscutivelmente maior do que o proposto pela boa fé objetiva. Isto porque, enquanto a esta última importa a consciência do agente acerca da prática de determinado ilícito para que ele se configure, à primeira basta que o desrespeito à norma geral de boa-fé processual tenha se materializado, independentemente daquilo que se passou no foro íntimo do sujeito que deu causa ao ilícito.

Nesse diapasão, DIDIER JR. (2015, p. 104) assevera:

$\mathrm{O}$ art. $5^{\circ}$ do CPC não está relacionado à boa-fé subjetiva, à intenção do sujeito processual: trata-se de uma norma que impõe condutas em conformidade

\footnotetext{
10 DIDIER JR., Fredie. Editorial 45. Bahia, 2008. Disponível em: <http://www.frediedidier.com.br/editorial/editorial-45/>. Acesso em: 01 fev. 2016.

11 THEODORO JR., Humberto et al. Novo CPC: Fundamentos e Sistematização. Rio de Janeiro: Forense, 2015. p. 135.
} 
com a boa-fé objetivamente considerada, independentemente da existência de boas ou más intenções. ${ }^{12}$

Conclui-se, finalmente, que a boa-fé subjetiva é um fato presente na psique dos sujeitos processuais, enquanto que a boa-fé objetiva é uma norma de comportamento a eles dirigida. ${ }^{13}$

\section{EVOLUÇÃO DO PRINCÍPIO DA BOA-FÉ PROCESSUAL}

\subsection{A BOA-FÉ NO CPC/1973}

O Código de Processo Civil de 1973 já contemplava a boa-fé como um dever de conduta das partes, em seu artigo 14, inciso II, que assim dispunha:

Art. 14. São deveres das partes e de todos aqueles que de qualquer forma participam do processo: (Redação dada pela Lei $\mathrm{n}^{\circ} 10.358$, de 27.12.2001)

II - proceder com lealdade e boa-fé.

Tal dispositivo, entretanto, era enxergado pela maior parte dos doutrinadores brasileiros como uma expressão da boa-fé subjetiva, ve-

12 DIDIER JR., Fredie. Curso de Direito Processual Civil: Introdução ao Direito Processual Civil, Parte Geral e Processo de Conhecimento. 17 ed. Salvador: JusPodvm, v.1, 2015. p. 104.

${ }^{13}$ TARTUCE, Flávio. Boa-fé Objetiva Processual: Reflexões quanto ao atual CPC e ao Projeto do Novo Código. In: Jusbrasil, 2014. Disponível em: <http://flaviotartuce.jusbrasil. com.br/artigos/121822496/boa-fe-objetiva-processual-reflexoes-quanto-ao-atual-cpc-e-aoprojeto-do-novo-codigo>. Acesso em: 01 fev. 2016. 
dando apenas os comportamentos imbuídos de intuitos dolosos de ofender direitos alheios. ${ }^{14}$

A essa corrente, alinhavam-se NERY JR. e NERY, ao afirmarem que a boa-fé era um fato, que somente se podia presumir, não conferindo a mesma o caráter de regra de conduta. ${ }^{15}$

Porém, mesmo antes do advento do CPC/2015, já havia expressão jurisprudencial e doutrinária apontando no sentido de que o inciso II do artigo 14 do CPC/1973 já conferia á boa-fé o caráter de cláusula geral processual, norma geral de conduta, corrente esta desde logo defendida por DIDIER JR. que ainda em menção ao antigo diploma processual, assim o defendia, vejamos: "Em verdade, não seria necessária qualquer enumeração das condutas desleais: O inciso II do art. 14 do CPC é bastante, exatamente por tratar-se de uma cláusula geral". ${ }^{16}$

Vejamos um julgado do Supremo Tribunal Federal, antes da entrada em vigor do novo diploma processual, mas já considerando a exigência do dever de boa-fé imposto aos participantes do processo:

$\begin{array}{lcr}\text { Ementa: EMBARGOS } & \text { DE } & \text { DECLARAÇÃO. } \\ \text { RECURSO INTERPOSTO } & \text { ANTES DA DA } \\ \text { PUBLICAÇÃO } & \text { DO } & \text { ACORDÃO. } \\ \text { CONHECIMENTO. } & \text { INSTRUMENTALISMO }\end{array}$
PROCESSUAL. PRECLUSÃO QUE NÃO PODE PREJUDICAR A PARTE QUE CONTRIBUI PARA A CELERIDADE DO PROCESSO. BOA-FÉ EXIGIDA DO ESTADO-JUIZ. DOUTRINA. RECENTE JURISPRUDÊNCIA DO PLENÁRIO. MÉRITO. ALEGAÇÃO DE OMISSÃO E CONTRADIÇÃO. INEXISTÊNCIA. RECURSO CONHECIDO E REJEITADO.

[...] As preclusões se destinam a permitir o regular e célere desenvolvimento do feito, por isso que não é possível penalizar a parte que age de boa-fé e contribui para o progresso da marcha processual com o não conhecimento do recurso, arriscando conferir

14 DIDIER JR., Fredie. Curso de Direito Processual Civil: Introdução ao Direito Processual Civil, Parte Geral e Processo de Conhecimento. 17 a ed. Salvador: JusPodvm, v.1, 2015. p. 207.

${ }^{15}$ DIDIER JR., Fredie. Curso de Direito Processual Civil: Teoria Geral do Processo e Processo de Conhecimento. 11 a ed. Salvador: JusPodvm, v.1, 2009. p. 152.

${ }^{16}$ Ibidem, p. 45. 
o direito à parte que não faz jus em razão de um purismo formal injustificado. 4. O formalismo desmesurado ignora a boa-fé processual que se exige de todos os sujeitos do processo, inclusive, e com maior razão, do Estado-Juiz, bem como se afasta da visão neoconstitucionalista do direito, cuja teoria proscreve o legicentrismo e o formalismo interpretativo na análise do sistema jurídico, desenvolvendo mecanismos para a efetividade dos princípios constitucionais que abarcam os valores mais caros à nossa sociedade (COMANDUCCI, Paolo. Formas de (neo) constitucionalismo: un análisis metateórico. Trad. Miguel Carbonell. In: Isonomía. Revista de Teoría y Filosofía del Derecho, $\mathrm{n}^{\mathrm{o}}$ 16, 2002). [...]

(STF - HC: 101132 MA, Relator: Min. LUIZ FUX, Data de Julgamento: 24/04/2012, Primeira Turma, Data de Publicação: ACÓRDÃO ELETRÔNICO DJe-099 DIVULG 21-05-2012 PUBLIC 22-052012).

Observa-se, nesse julgado do ano de 2012, que fora considerada a boa-fé em seu aspecto objetivo, como dever de conduta dirigido àqueles que participam do processo, especificamente ao Estado-Juiz ao prolatar suas decisões.

No mesmo sentido, também se posicionou o Supremo Tribunal de Justiça, ao julgar recurso com intuito manifestamente protelatório, vejamos:

TERCEIROS DECLARATÓRIOS EM RECURSO ESPECIAL. RECURSO INFUNDADO. NÍTIDO CARÁTER PROTELATÓRIO. DESVIRTUAMENTO DO CÂNONE DA AMPLA DEFESA. ABUSO DE DIREITO. DETERMINAÇÃO DE REMESSA DOS AUTOS AO STF. EMBARGOS NÃO CONHECIDOS. 1. A recorribilidade vazia, infundada, como in casu, tão somente com nítido intuito protelatório, configura abuso do direito de recorrer e é inadmissível em nosso ordenamento jurídico, notadamente em respeito aos postulados da lealdade e boa-fé 
processual, além de afigurar desvirtuamento do próprio cânone da ampla defesa. [...].

(STJ - EDcl nos EDcl nos EDcl no REsp: 1327433 PR 2012/0116999-6, Relator: MARIA THEREZA DE ASSIS MOURA, Data de Julgamento: 18/12/2014, T6 - SEXTA TURMA, Data de Publicação: DJe 04/02/2015).

Conforme observado, os tribunais superiores já vinham se posicionando no sentido de conferir à boa-fé o tratamento de dever de conduta. No julgado acima, a parte que incorreu em abuso de direito de recorrer foi penalizada com o não conhecimento de seu recurso, dada a sua inobservância do dever de agir com boa-fé.

Em todo caso, a despeito da divergência doutrinária e jurisprudencial que tenha havido nesse sentido até o marco do advento do CPC de 2015, fato é que somente após a positivação das denominadas normas fundamentais processuais é que a discussão foi superada e a boa-fé ganhou, definitivamente, o caráter de norma.

\subsection{A BOA-FÉ NO CPC/2015}

Segundo DIDIER JR. e PEIXOTO, o artigo $5^{\circ}$ do Novo Código de Processo Civil Brasileiro trata-se de uma reprodução do Código de Direito Processual Suíço, que em seu artigo 52, denota a boa-fé como um dever de conduta dirigido a todos os sujeitos processuais. ${ }^{17}$

Considerando a evolução do debate pelo nosso estudo até o presente momento; onde já fora pontualmente explanado o papel das normas processuais fundamentais; a inserção da boa-fé objetiva como o tal pelo Novo CPC; seu conceito e importância como cláusula geral processual, entendemos que a posição assumida pela boa-fé no novo diploma processual já fora elucidada nos tópicos anteriores.

Todavia, cumpre ressaltar que a expressão da boa-fé objetiva pelo Novo CPC extrapola sua prevalência como uma regra de conduta a ser observada pelos sujeitos processuais, exercendo ainda a função her-

17 DIDIER JR., Fredie; PEIXOTO, Ravi Medeiros. O Novo CPC Online: curso de atualização. Jan - 2016. Notas de aula. Novo Código de Processo Civil: Comparativo com o Código de 1973. 1ª. ed. Salvador: JusPodvm, 2015. p. 821. 
menêutica e também norteadora das decisões a serem tomadas no curso do processo.

Sobre tal importância, assevera ALVIM:

No texto do NCPC, a expressão é referida em pelo menos três dispositivos distintos, quais sejam: i) artigo $5^{\circ}$ - como dever de todo e qualquer sujeito do processo; ii) artigo $322, \S 2^{\circ}-$ como princípio norteador da interpretação do pedido formulado; e iii) artigo $489, \S 3^{\circ}$ - como princípio norteador da interpretação das decisões judiciais. ${ }^{18}$

Tendo isso superado, interessa que prossigamos à análise do alcance da aludida norma, a fim de que passemos a entender de que forma ela se aplica a todos os sujeitos e em quaisquer fases processuais.

\section{O ALCANCE DA BOA-FÉ OBJETIVA PROCESSUAL}

Desde o CPC de 1973, a boa-fé era direcionada a todos os participantes do processo, o que foi ratificado pelo Novo Diploma Processual, que além de reiterar sua imposição obrigatória a todos os sujeitos processuais, ainda conferiu-lhe o status de norma processual fundamental, de forma absolutamente inovadora, conforme anteriormente esclarecido.

Importa destacar que, ao direcionar a norma a "todos aqueles que de qualquer forma participam do processo", o artigo $5^{\circ}$ do NCPC não deixa dúvidas quanto ao direcionamento da norma não somente às partes litigantes, mas também aos juízes, tribunais e demais participantes do processo. ${ }^{19}$

Anotam ainda, quanto ao alcance da boa-fé objetiva, o seguinte:

\footnotetext{
${ }^{18}$ ALVIM, Rafael. A boa-fé no novo CPC. In: Instituto de Direito Contemporâneo. 2015. Disponível em: <http://www.cpcnovo.com.br/blog/2015/01/14/a-boa-fe-no-novo-cpc/> Acesso em: 02 fev. 2016. p. 1.

19 THEODORO JR., Humberto et al. Novo CPC: Fundamentos e Sistematização. Rio de Janeiro: Forense, 2015.
} 
Todos os participantes do processo devem comportar-se de acordo com a boa-fé: partes, advogados, membro do Ministério Público, da Defensoria Pública e Juiz. Também aqueles que participam apenas episodicamente do processo também estão sujeitos ao dever de boa-fé processual. $^{20}$

Sob este prisma, pode-se afirmar que não importa a posição assumida no processo, se dele participar, o sujeito deve portar-se de acordo com a boa-fé. Conciliadores, peritos, serventuários e membros do Poder Judiciário em geral, por exemplo, não se esquivam do dever de boa-fé, insculpido no artigo $5^{\circ}$ do Novo CPC.

\subsection{CONSEQUÊNCIAS E REPERCUSSÕES PRÁTICAS DA BOA-FÉ PROCESSUAL}

Tendo em vista tudo o que fora explanado até o presente momento acerca da boa-fé objetiva processual, importa que o debate proposto pelo estudo ora desenvolvido seja finalizado analisando as possíveis repercussões práticas da aludida norma.

DIDIER JR., ao tratar das consequências da boa-fé processual, o faz seguindo a divisão proposta pela doutrina alemã, listando, de maneira consecutiva: a proibição de agir de má-fé; a vedação ao venire contra factum proprium; a proibição de abusos de direitos processuais; e, finalmente, a supressio processual. ${ }^{21}$

Seguindo a didática proposta pelo mesmo autor, passemos a analisar cada uma dessas consequências.

A proibição de agir de má-fé trata-se de uma expressão da boafé subjetiva, que fora encampada pela boa-fé objetiva, eis que esta última é mais abrangente. Trata-se da proibição de práticas processuais eivadas

\footnotetext{
${ }^{20}$ MARINONI, Luiz Gulherme; ARENHART, Sérgio Cruz; MITIDIERO, Daniel. Novo Código de Processo Civil Comentado. $1^{\text {a }}$. ed. São Paulo: Editora Revista dos Tribunais, 2015. p. 99.

21 DIDIER JR., Fredie. Curso de Direito Processual Civil: Introdução ao Direito Processual Civil, Parte Geral e Processo de Conhecimento. $17^{\mathrm{a}}$ ed. Salvador: JusPodvm, v.1, 2015. p. 111.
} 
de má intenção, vedando o abuso de posições jurídicas, por quaisquer das partes. (MARINONI, ARENHART e MITIDIERO, 2015).

Exemplo dessa consequência é a penalização processual imposta àquele que litiga de má-fé, denotada pelos artigos 79 e 80 do Novo CPC.

A vedação ao venire contra factum proprium, por sua vez, refere-se à vedação de prática de comportamentos processuais contraditórios e incoerentes. Segundo TARTUCE (2013), essa aplicação pragmática da boa-fé preza pela razoabilidade dos atos praticados por determinado sujeito processual, de sorte a não permitir que ele assuma, em um mesmo processo, posições diametralmente opostas.

Por exemplo, não é razoável admitir que uma parte, oferecendo determinado bem à penhora na fase de execução, posteriormente alegue que o mesmo seja impenhorável, porque essa posição, além de incoerente, provoca a quebra de confiança entre as partes, configurando clara violação o dever de boa-fé.

No tocante ao abuso de direitos processuais, DIDIER JR. (2015, p. 111), afirma que "Qualquer abuso de direito no processo é proibido pela incidência do princípio da boa-fé processual.".

Exemplo disso é o abuso do direito de recorrer, ilícito processual praticado pela parte que interpõe recurso com intuito manifestamente protelatório, visando conferir morosidade ao processo (Inciso VII, artigo 80, NCPC).

Finalmente, temos a Verwirkung, também denominada de supressio processual, a qual, segundo DIDIER JR. (2015, p. 112), adotando a concepção de Menezes de Cordeiro, afirma corresponder à "perda de uma situação jurídica ativa, pelo não exercício em lapso de tempo tal que gere no sujeito passivo a expectativa legítima de que a situação jurídica não seria mais exercida".

Em face dessa aplicação, vale dizer que algumas faculdades processuais não se prolongam no tempo, desde que não tenham sido exercidas por tão grande lapso temporal, de modo a gerar na outra parte a justa confiança de que não mais serão invocadas.

Como exemplos da aplicação da supressio processual, DIDIER JR (2015, p. 112) cita: 
a) perda do poder do juiz de examinar a admissibilidade do processo, após anos de tramitação regular, sem que ninguém houvesse suscitado a questão; b) perda do direito da parte de alegar nulidade, em razão do lapso de tempo transcorrido, que fez surgir a confiança de que não mais alegaria nulidade.

Sabiamente, THEODORO JR. et. al. (2015), afirma que a supressio corresponde à preclusão de um poder processual, que por não ter sido exercido ao tempo adequado, não pode mais ser invocado.

\section{CONSIDERAÇÕES FINAIS}

A boa-fé processual encontra-se há muito tempo presente no ordenamento jurídico brasileiro, inclusive já era abordada pelo CPC/1973 (art. 14, inciso II), como um dever dirigido às partes e a todos aqueles que participassem do processo.

Todavia, devido o aludido dispositivo não ter dado à boa-fé processual o tratamento de norma, havia quem defendesse que ele dispunha acerca da boa-fé subjetiva, caracterizada como um fato, passível de mera presunção, pois intimamente ligado ao estado psicológico do sujeito que praticava determinado ato processual.

O Novo Diploma Processual superou a discussão até então havida, pois consagrou a boa-fé processual como uma norma processual de caráter fundamental, que por sua essência e natureza, é de observância obrigatória por todos aqueles que participam do processo, inclusive pelo próprio Estado-Juiz, em todas as fases processuais.

Importante destacar que as aplicações práticas e consequências da inobservância à norma processual fundamental em questão serão ainda delineadas pelos tribunais, porque, conforme denotado em momentos anteriores do presente estudo, o artigo $5^{\circ}$ do CPC/2015 trata-se de uma cláusula geral processual, uma hipótese normativa ampla, que não define a boa-fé processual, nem tampouco prevê as consequências de sua inobservância.

Conclui-se, finalmente, que inserção da aludida norma pelo novo Diploma Processual Civil (artigo $5^{\circ}, \mathrm{CPC} / 2015$ ) possui o condão de 
conferir maior segurança jurídica às relações processuais, inserindo, de uma vez por todas, o dever de cooperação e lealdade entre as partes e demais participantes do processo, a fim de que todos contribuam para o melhor deslinde processual.

\section{REFERÊNCIAS BIBLIOGRÁFICAS}

ALVIM, Rafael. A boa-fé no novo CPC. In: Instituto de Direito Contemporâneo. 2015. Disponível em: <http://www.cpcnovo.com.b r/blog/2015/01/14/a-boa-fe-no-novo-cpc/> Acesso em: 02 fev. 2016.

BRASIL. Supremo Tribunal Federal. Embargos de Declaração no Habeas Corpus HC $\mathbf{n}^{\mathbf{0}}$ 101132. Relator: Ministro Luiz Fux. Disponível em: <http://stf.jusbrasil.com.br/jurisprudencia/21810496/embdecl-nohabeas-corpus-hc-101132-ma-stf. Acesso em: 21 ago. 2016. . Superior Tribunal de Justiça. Terceiros Declaratórios em Recurso Especial. EDcl nos EDcl nos EDcl no REsp 1327433 PR 2012/0116999-6. Relator: Ministra Maria Thereza de Assis Moura. Disponível em: <http://stj.jusbrasil.com.br/jurisprudencia/165419862/embargosde-declaracao-nos-embargos-de-declaracao-nos-embargos-dedeclaracao-no-recurso-especial-edcl-nos-edcl-nos-edcl-no-resp1327433-pr-2012-0116999-6>. Acesso em: 21 ago. 2016.

DIDIER JR., Fredie. Curso de Direito Processual Civil: Teoria Geral do Processo e Processo de Conhecimento. $11^{\mathrm{a}} \mathrm{ed}$. Salvador:JusPodvm, v.1, 2009.

- Curso de Direito Processual Civil: Introdução ao Direito Processual Civil, Parte Geral e Processo de Conhecimento. 17 ${ }^{\mathrm{a}}$ ed. Salvador: JusPodvm, v.1, 2015.

Editorial 45. Bahia, 2008. Disponível em: <http://www.frediedidier.com.br/editorial/editorial-45/>. Acesso em: 01 fev. 2016.

; PEIXOTO, Ravi Medeiros. O Novo CPC Online: curso de atualização. Jan - 2016. Notas de aula. Novo Código de Processo Civil: Comparativo com o Código de 1973. $1^{\text {a }}$. ed. Salvador: JusPodvm, 2015. 851 p. 
MARINONI, LUIZ GULHERME; ARENHART, SÉRGIO CRUZ; MITIDIERO, DANIEL. Novo Código de Processo Civil Comentado. $1^{\text {a }}$. ed. São Paulo: Editora Revista dos Tribunais, 2015.

SANTOS, Leide Maria Gonçalves. A Boa-Fé Objetiva no Processo Civil: A Teoria dos Modelos de MIGUEL REALE aplicada à Jurisprudência Brasileira Contemporânea. 2008. 287 f. Dissertação (Mestrado em Direito Processual Civil) - Universidade Federal do Espírito Santo, Vitória, 2008. Disponível em: <http://www.dominiopublico.gov.br/download/teste/arqs/cp087 247.pdf>. Acesso em: 02 fev. 2016.

TARTUCE, Flávio. Boa-fé Objetiva Processual: Reflexões quanto ao atual CPC e ao Projeto do Novo Código. In: Jusbrasil, 2014. Disponível em: <http://flaviotartuce.jusbrasil.com.br/artigos/121822496/boa-feobjetiva-processual-reflexoes-quanto-ao-atual-cpc-e-ao-projeto-donovo-codigo>. Acesso em: 01 fev. 2016.

THEODORO JR., Humberto et al. Novo CPC: Fundamentos e Sistematização. Rio de Janeiro: Forense, 2015. 
